Research

\title{
Coordinate enhancement of transgene transcription and translation in a lentiviral vector Alper Yilmaz ${ }^{1,5}$, Soledad Fernandez ${ }^{3,4}$, Michael D Lairmore ${ }^{1,2,4,5}$ and Kathleen Boris-Lawrie*1,2,4,5
}

\author{
Address: ${ }^{1}$ Center for Retrovirus Research and Department of Veterinary Biosciences, The Ohio State University, Columbus, OH, 43210, USA, \\ 2Department of Molecular Virology, Immunology \& Medical Genetics, The Ohio State University, Columbus, OH, 43210, USA, ${ }^{3}$ Center for \\ Biostatistics, The Ohio State University, Columbus, OH, 43210, USA, ${ }^{4}$ Comprehensive Cancer Center, The Ohio State University, Columbus, OH, \\ 43210, USA and ${ }^{5}$ Molecular, Cellular \& Developmental Biology Graduate Program, The Ohio State University, Columbus, OH, 43210, USA \\ Email: Alper Yilmaz - yilmaz.11@osu.edu; Soledad Fernandez - fernandez.71@osu.edu; Michael D Lairmore - lairmore.1@osu.edu; \\ Kathleen Boris-Lawrie* - boris-lawrie.1@osu.edu \\ * Corresponding author
}

Published: 15 February 2006

Retrovirology 2006, 3:13 doi:10.1186/1742-4690-3-13
Received: 06 January 2006

Accepted: I5 February 2006

This article is available from: http://www.retrovirology.com/content/3/I/13

(C) 2006 Yilmaz et al; licensee BioMed Central Ltd.

This is an Open Access article distributed under the terms of the Creative Commons Attribution License (http://creativecommons.org/licenses/by/2.0), which permits unrestricted use, distribution, and reproduction in any medium, provided the original work is properly cited.

\begin{abstract}
Background: Coordinate enhancement of transgene transcription and translation would be a potent approach to significantly improve protein output in a broad array of viral vectors and nonviral expression systems. Many vector transgenes are complementary DNA (cDNA). The lack of splicing can significantly reduce the efficiency of their translation. Some retroviruses contain a 5 ' terminal post-transcriptional control element (PCE) that facilitates translation of unspliced mRNA. Here we evaluated the potential for spleen necrosis virus PCE to stimulate protein production from HIV-I based lentiviral vector by: I) improving translation of the internal transgene transcript; and 2) functionally synergizing with a transcriptional enhancer to achieve coordinate increases in RNA synthesis and translation.

Results: Derivatives of HIV-I SIN self-inactivating lentiviral vector were created that contain PCE and cytomegalovirus immediate early enhancer (CMV IE). Results from transfected cells and four different transduced cell types indicate that: I) PCE enhanced transgene protein synthesis; 2) transcription from the internal promoter is enhanced by CMV IE; 3) PCE and CMV IE functioned synergistically to significantly increase transgene protein yield; 4) the magnitude of translation enhancement by PCE was similar in transfected and transduced cells; 5) differences were observed in steady state level of PCE vector RNA in transfected and transduced cells; 6) the lower steady state was not attributable to reduced RNA stability, but to lower cytoplasmic accumulation in transduced cells.

Conclusion: PCE is a useful tool to improve post-transcriptional expression of lentiviral vector transgene. Coordinate enhancement of transcription and translation is conferred by the combination of PCE with CMV IE transcriptional enhancer and increased protein yield up to II to I7-fold in transfected cells. The incorporation of the vector provirus into chromatin correlated with reduced cytoplasmic accumulation of PCE transgene RNA. We speculate that epigenetic modulation of promoter activity altered cotranscriptional recruitment of RNA processing factors and reduced the availability of fully processed transcript or the efficiency of export from the nucleus. Our results provide an example of the dynamic interplay between the transcription and posttranscription steps of gene expression and document that introduction of heterologous gene expression signals can yield disparate effects in transfected versus transduced cells.
\end{abstract}




\section{Background}

A challenge inherent to many gene delivery systems is efficient expression of the vector transgene. Enhancement of transcription has been a thoroughly investigated target to improve vector gene expression. For example, introduction of a constitutive viral transcription enhancer or a tissue-specific cellular promoter has been utilized widely to stimulate synthesis of vector transgene RNA [1-4]. In addition to high level synthesis of RNA, efficient post-transcriptional expression is a potent target to improve vector gene expression by maximizing the protein yield per molecule of transgene transcript. Notably, many vector transgenes are complementary DNA (cDNA) copies of the natural intron-containing gene. The elimination of introns is an advantageous approach for reducing of the size of the vector transcript to conform to the packaging capacity of the vector virus. This approach is advantageous in vectors with limited packaging size, as is the case for retroviral vectors $[5,6]$. However the elimination of intronic sequences can significantly reduce protein yield because the process of splicing promotes the translation of introncontaining genes [7-10]. This activity is attributed to a multiprotein complex that is deposited at exon junctions as a consequence of splicing $[11,12]$. The elimination of intronic sequences can reduce protein yield in a range of a factor of 2 to $30[13,14]$. Therefore the elimination of introns from a transgene may reduce protein yield per molecule of transgene transcript.

Recently, a unique 5 ' terminal positive posttranscriptional control element (PCE) was identified in the 5 ' long terminal repeat (LTR) of two simple retroviruses, spleen necrosis virus (SNV) and Mason-Pfizer monkey virus (MPMV) $[15,16]$. PCE stimulates translation of non-spliced RNA $[16,17]$. SNV PCE is a compact $165 \mathrm{nt}$ orientationdependent RNA element that is composed of two functionally redundant stem-loop structures that present unpaired nucleotides for interaction with the ubiquitous host protein RNA helicase A [[18], T. Hartman and K. Boris-Lawrie, manuscript submitted]. PCE is not strictly position-dependent and sustains activity when repositioned to at least $300 \mathrm{nt}$ downstream of the transcription start site [17]. In addition, PCE facilitates expression of unspliced gag-pol RNA of HIV-1 and the parental retrovirus, SNV [[15], T. Hartman, S. Hull and K. Boris-Lawrie, unpublished].

Results from experiments with cDNA expression plasmids determined that PCE stimulates protein yield from nonspliced mRNA by 7 to 10 -fold [17]. Quantitative RNA analysis showed that the increased protein production was not attributable to modulation of steady state RNA level or nuclear export. Rather, the increased protein production was due to increased ribosome association. Additional experimentation determined that PCE does not

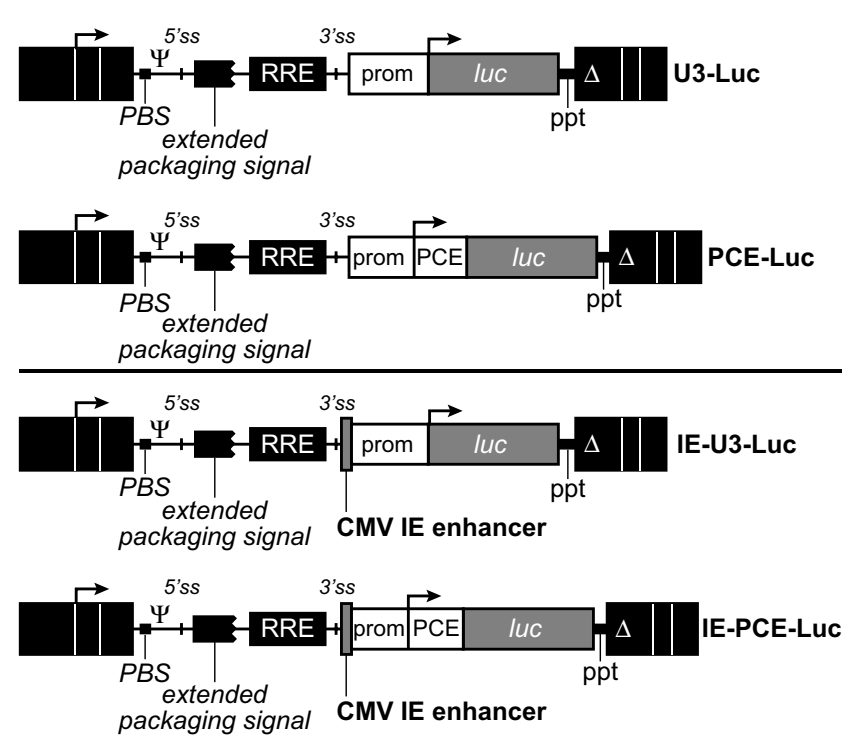

Figure I

Genomic structure of self-inactivating lentiviral vectors that lack or contain PCE translation enhancer.

HIV-I based lentiviral vectors were derived from pHR' [36]. Black rectangles represent HIV-I long terminal repeats; PBS, primer binding site; $\Psi$, the core packaging signal; extended packaging signal that corresponds to $350 \mathrm{nt}$ HIV-I gag open reading frame; 5 'ss and 3'ss, splice sites; RRE, Rev responsive element; PPT, polypurine tract; $\Delta$ indicates deletion of HIV-I promoter sequences between $-4 \mid 8$ to - I8; white boxes represent SNV sequences; Prom corresponds to spleen necrosis virus (SNV) U3 promoter; PCE is the $165 \mathrm{nt}$ RU5 region of SNV; CMV IE, cytomegalovirus immediate early enhancer.

function as an internal ribosome entry site to stimulate internal initiation on bicistronic reporter RNA [17]. These findings and the determination that PCE requires nuclear interactions for stimulation of translation [19] indicates that PCE is a novel 5' terminal cap-dependent translation enhancer of nonspliced RNA.

In addition to its functional activity, other properties make PCE an excellent candidate for improving translational efficiency of vector transgene mRNA. First, PCE functions in a wide variety of cells in concert with ubiquitously expressed host effector protein. Second, PCE stimulates translation of non-spliced mRNA template, which is a common form of vector transgene mRNA. Third, PCE exhibits flexibility in position relative to the transcription start site, which provides versatility during vector construction. The first goal of this study was to test the hypothesis that SNV PCE increases the translational efficiency of lentiviral vector transgene mRNA. In addition, we reasoned that coordinate enhancement of transgene transcription and translation has significant potential for synergistically improving efficiency of transgene expres- 
Table I: The combination of PCE and CMV IE increased Luc activity in transfected 293 cells

\begin{tabular}{lcccc}
\hline & \multicolumn{4}{c}{$\begin{array}{c}\text { Luc activity (Relative Light Units) } \\
\text { Replicate Experiment }\end{array}$} \\
\cline { 2 - 5 } Vector & 1 & 2 & 3 & 4 \\
\cline { 2 - 5 } & & $3,809 \pm 207(1)$ & $3,605 \pm 3(1)$ & $3,796 \pm 700(1)$ \\
U3-Luc & $2,955 \pm 171(1)^{\mathrm{b}}$ & $19,644 \pm 343(5.1)^{*}$ & $14,756 \pm 382(4.0)^{*}$ & $15,110 \pm 842(3.9)^{*}$ \\
PCE-Luc & $20,810 \pm 559(7.0)^{*}$ & $13,174 \pm 228(3.4)$ & $12,945 \pm 2,677(3.6)$ & $16,676 \pm 435(4.4)$ \\
IE-U3-Luc & $10,490 \pm 159(3.5)$ & $48,085 \pm 90(12.6)^{*}$ & $39,485 \pm 7,303(11)^{*}$ & $50,424 \pm 1,952(13)^{*}$ \\
IE-PCE-Luc & $49,870 \pm 28(16.8)^{*}$ & & \\
\hline
\end{tabular}

a Two-days post-transfection with the indicated vector, which encodes firefly Luciferase (Luc) and Renilla luciferase control plasmid, total cellular protein was harvested and relative Luciferase levels were measured by chemiluminescence assay. Luc level was standardized to cotransfected Renilla Luc and results are presented of four independent experiments performed in duplicate or triplicate. ANOVA with repeated measures determined that increases in response to PCE and IE were significant as indicated by * ( $\mathrm{p}$-values of 0.0008 and $<0.000 \mathrm{I}$, respectively).

$\mathrm{b}()$, Fold difference relative to U3-luc vector.

sion in lentiviral vector and in other gene expression systems. The promoter of the lymphotropic SNV is constitutively active in a wide variety of cells types from different species [15,20-22]. The promoter encodes two 46 and 23 base-pair repeats with strong enhancer activity and does not require virus-encoded transcription factor to regulate transcriptional efficiency [21]. We constructed a series of vectors to test whether the combination of PCE and a strong heterologous transcriptional enhancer yields a synergistic increase in protein production. Quantitative analysis of RNA and protein levels were used to characterize the effect of PCE on vector RNA in transfected and transduced cells. The results indicate that PCE and cytomegalovirus immediate early (CMV IE) transcription enhancer function synergistically to significantly improve transgene protein output.

\section{Results \\ CMV IE and PCE function synergistically to increase protein output in transfected cells}

A series of HIV-1 based self-inactivating lentiviral vectors were constructed that lack or contain PCE and CMV IE (Figure 1). The vector luciferase (luc) transgene was expressed from an internal transcription unit under the control of the constitutive SNV promoter. The vectors lack or contain SNV PCE and the CMV IE transcriptional enhancer and are designated U3-Luc, PCE-Luc, and IE-U3Luc and IE-PCE-Luc, respectively.

The vectors were transfected into 293 cells and two days post-transfection, total cellular protein was harvested for Luc assay. Comparison of U3-Luc and PCE-Luc demonstrated that PCE increased Luc activity by 4 to 7 -fold (Table 1). Introduction of CMV IE produced a 2.4- to 4.4fold increase in Luc production (compare U3-Luc with IEUE-Luc and PCE-Luc with IE-PCE-Luc). Comparison of U3-Luc and IE-PCE-Luc indicated that the combination of PCE and CMV IE produced a cumulative 11 to 17 -fold increase in protein production. The results indicate that
PCE and CMV IE function synergistically to increase gene expression.

\section{PCE increases the translational efficiency of lentiviral vector RNA}

Northern blot analysis of total cellular RNA was performed to compare the levels of steady state transgene mRNA. Three replicate Northern blot experiments were performed with radiolabeled probe complementary to the luc open reading frame or glyceraldehyde-3-phosphate dehydrogenase (gapdh) to control for RNA loading. The experiments demonstrated that the vectors express luc transcript of the expected size and that PCE-Luc and U3Luc displayed similar levels of steady state RNA (Figure 2A). In this representative experiment, luc mRNA levels from PCE-Luc and U3-Luc RNA were $2.2 \times 10^{5}$ phosphorimager units $(\mathrm{PI})$ and $1.8 \times 10^{5} \mathrm{PI}$, respectively (Figure $2 \mathrm{~B}$ ). Introduction of CMV IE produced an equivalent 2-fold increase in luc RNA level in either the presence or absence of PCE (IE-PCE-Luc, $5.0 \times 10^{5}$ PI and IE-U3-Luc, $3.6 \times 10^{5} \mathrm{PI}$ ) (Figure 2B). Comparison of the level of Luc protein to luc RNA showed that addition of PCE correlated with a 4-fold increase in Luc protein (Figure 2B). Ribosomal profile analysis determined that ribosome association was greater for the PCE-containing vector than the PCE-lacking vector (data not shown). The results indicate that combination of CMV IE and PCE yielded a synergistic increase in vector transgene expression in the transfected cells.

\section{IE and PCE function synergistically to increase protein yield in transduced cells}

Next we sought to determine whether the coordinate increases in vector transgene expression were sustained in transduced cells. The vector viruses were propagated by co-transfection of 293T cells with each vector, HIV-1 helper plasmid and VSV-G expression plasmid. ELISA was used to measure the capsid Gag levels and equal amounts of Gag were used for transduction by spinoculation of 
A

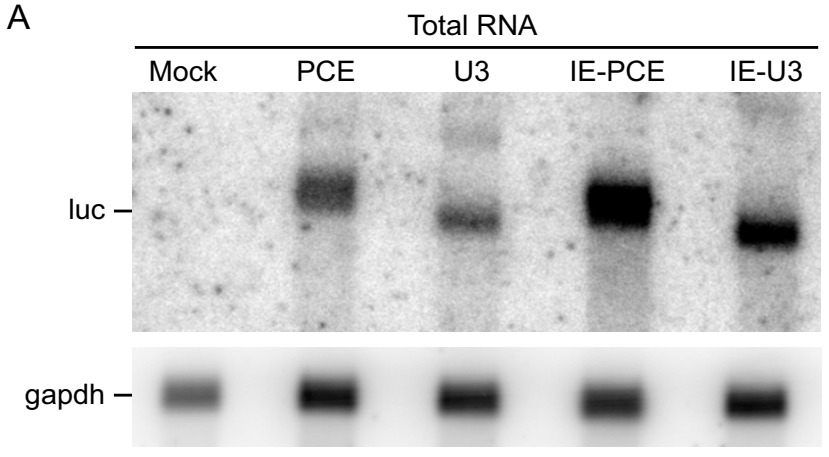

B

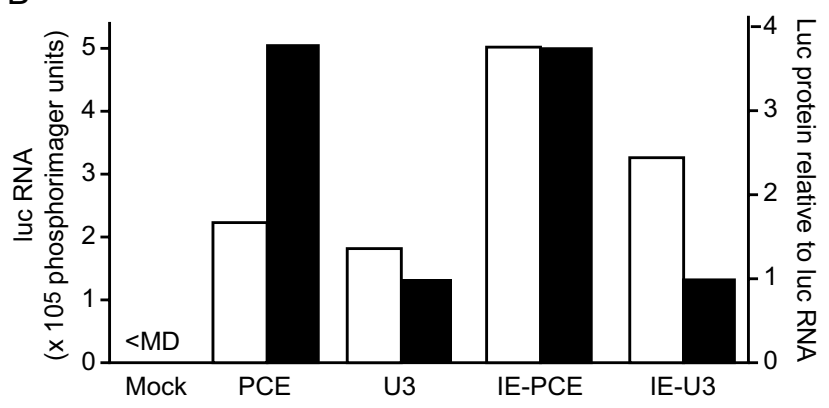

Figure 2

PCE increases lentiviral vector transgene activity in transfected cells. (A) Northern blot analysis of total RNA that was isolated $48 \mathrm{hrs}$ after transfection with the indicated vector and hybridized with DNA probe complementary to luc open reading frame or gapdh loading control. The gapdh level was used to standardized minor differences in RNA sample concentration. (B) Graphic representation of data from (A) with white bars indicating the luc RNA levels standardized to gapdh loading control. Black bars indicate translational efficiency relative to the corresponding U3 vector. Translational efficiency is defined as the ratio of Luc activity in these samples to luc mRNA in (A).

HeLa human fibroblast cells, CEM-A human T cells, D17 canine osteosarcoma cells, and 293 human embryonic kidney cells. Forty-eight hours post-transduction, the transduced cells were harvested and Luc activity in total cellular protein was measured.

The PCE-containing vectors exhibited increased Luc production in all four target cells (Table 2). The magnitude of increase in response to PCE was 2 to 4 -fold (Table 2, compare U3-Luc and PCE-Luc). The magnitude of increase in response to CMV IE was an additional 2-fold (Table 2, compare U3-Luc with IE-U3-Luc and PCE-Luc with IEPCE-Luc). Comparison of U3-Luc and IE-PCE-Luc indicated that the combination of PCE and CMV-IE produced a cumulative 4 -fold increase in transgene protein produc- tion. These increases were lower in magnitude than the increases observed in the transfected cells (Table 1). Realtime PCR was performed to evaluate provirus copy number and revealed similar levels of vector provirus in transduced 293 cells. In this representative experiment, the copy numbers for PCE-Luc, U3-luc, IE-PCE-Luc and IE-U3-Luc were $4.24 \times 10^{3} ; 6.31 \times 10^{3} ; 3.83 \times 10^{3}$; and $2.07 \times 10^{3}$ copies $/ \mathrm{ng}$, respectively. The results showed that the transduction efficiency was similar between the vectors and was not affected by introduction of PCE or CMV IE.

\section{Vector transduction correlates with reduced cytoplasmic accumulation of PCE-Luc RNA}

Northern blot assay was used to evaluate steady state luc RNA levels in three replicate experiments. Northern blot analysis of total cellular RNA determined that after transduction, the PCE-containing vectors expressed less steady state luc RNA compared to their PCE-lacking derivative (compare $\mathrm{U} 3$ and PCE, IE-U3 and IE-PCE, Figure 3A). Figure $3 \mathrm{~B}$ summarizes the luc RNA levels standardized to gapdh loading control for this particular experiment. This trend differed from the results in transfected cells, wherein the steady state luc levels were not lower in the presence of PCE (Figure 2). Introduction of CMV IE produced an equivalent 2-fold increase in luc RNA level in either the presence or absence of PCE, which was similar in magnitude to the increase in transfected cells (compare PCE and IE-PCE, U3 and IE-U3, Figure 2). Two of the possible explanations for the lower steady state luc RNA in response to PCE are that PCE lowers the cytoplasmic accumulation or the stability of the luc transcript.

Quantitative analysis of nuclear and cytoplasmic RNA levels was used to investigate possible differences in cytoplasmic accumulation. The transduced cells were fractionated into nucleoplasm and cytoplasm, RNA was harvested and subjected to reverse transcription, and cDNA levels were quantified by real time PCR. Control reactions with actin primers were used to control for minor differences in sample loading. Similar to the Northern analysis of total RNA, the PCE-containing luc RNAs were less abundant in the nucleoplasm and cytoplasm (Table 3, compare U3-Luc with PCE-Luc, IE-U3-Luc with IE-PCE-Luc). Moreover, the accumulation of PCE-Luc RNA in the cytoplasm was lower by a factor of 3 . Western analysis was used to verify appropriate fractionation of the nucleoplasm and cytoplasm. Histone $\mathrm{H} 1$ was present exclusively in the nuclear fractions and $\beta$-tubulin was present exclusively in the cytoplasmic fractions (Figure 4). Immunoblotting with actin verified equivalent sample loading among the samples. The results indicate that PCE-containing luc RNA exhibits lower cytoplasmic accumulation and this difference is proportional to the reduction observed in steady state luc mRNA. 
Table 2: The combination of PCE and CMV IE increased Luc activity in transduced cells

\begin{tabular}{|c|c|c|c|c|}
\hline \multirow[b]{2}{*}{ Vector } & \multicolumn{4}{|c|}{$\begin{array}{l}\text { Luc activity (Relative Light Units) } \\
\text { Replicate Experiment }\end{array}$} \\
\hline & $\mathrm{HeLa}$ & CEM-A & DI7 & 293 \\
\hline U3-Luc & $13,639 \pm 2,150(\mathrm{I})^{\mathrm{b}}$ & $17,100 \pm 524(1)$ & $18,093 \pm 349(1)$ & $15,099 \pm 539(1)$ \\
\hline PCE-Luc & $51,998 \pm 3108(3.8)^{*}$ & $52,372 \pm 3,354(3.0)^{*}$ & $50,4 \mid 2 \pm 2,997(2.7)^{*}$ & $27,294 \pm 1,173(1.8)^{*}$ \\
\hline IE-U3-Luc & $N^{c}$ & ND & ND & $26,197 \pm 95(1.7)$ \\
\hline IE-PCE-Luc & ND & ND & ND & $59,620 \pm 286(3.9)$ \\
\hline
\end{tabular}

a Equivalent vector virus particles were measured by Gag p24 ELISA and $4 \times 10^{5} \mathrm{pg}$ Gag was used to transduce the indicated target cell lines. Total cellular protein was harvested 48 hrs post-transduction and equivalent protein was subject to Luciferase assay. Standard deviations were calculated from results of two or more replicate experiments. ANOVA with repeated measures determined that increases in response to PCE were significant, (p-value of 0.017 ).

b (), Fold difference relative to U3-luc vector.

To investigate the possibility that PCE reduced the stability of the transgene mRNA, the transduced cells were treated with actinomycin D for intervals between 0 and 18 hrs and total cellular RNA was subjected to the Northern analysis. Similar to the Northern analysis shown in Figure 3 , the PCE-containing luc RNAs exhibited lower steady state levels compared to the PCE-lacking controls (compare PCE and U3 in Figure 5A, compare IE-PCE and IE-U3 in Figure 5B). In contrast to the differences in luc transcript, the abundance of gapdh loading control was similar among the samples. As shown graphically in Figure 5C and 5D, the decay kinetics of these PCE-containing luc RNAs were no faster than the PCE-lacking control RNAs. The results indicate that PCE did not reduce luc RNA stability. These results taken together with the RT-real time PCR results indicate that the lower steady state level of PCE-Luc RNA is not attributable to reduced RNA stability, but to lower cytoplasmic accumulation. Comparison of the level of Luc activity per molecule of luc RNA present in the cytoplasm indicated that PCE increased Luc protein yield 5 to 6 -fold in transduced cells (Table 3). These results indicate that despite the reduction of cytoplasmic accumulation of PCE-luc RNA in transduced cells, PCE translation enhancement activity was sustained. We conclude that the magnitude of translational enhancement is similar in transfected and transduced cells.

\section{Discussion}

Work presented here shows that the PCE can stimulate an increase in lentiviral vector transgene translation. This activity of PCE functioned in synergy with a heterologous transcriptional enhancer and produced a significant 11 to 17-fold increase in gene expression in transfected cells. The presence of PCE is associated with a lower steady state of the transgene mRNA in transduced 293 cells but is not attributable to reduced RNA stability. It is generally accepted that the abundance and localization of an mRNA may be different when expressed from transfected DNA or from an integrated vector in infected cells. An explanation for this observation is that activity of an integrated promoter in a transduced cell is modulated in relation to the local chromatin structure. For example, Williams et al. [23] found that binding of histone deacetylase enzyme HDAC1 to the LTR of an HIV-1 provirus induced alterations in the chromatin structure that disrupted binding of RNA polymerase II and silenced transcription. Additionally, Hofmann et al. showed that methylation of the promoter of a lentiviral vector provirus led to transcriptional inactivation [24]. A possible explanation for the lower steady state level of PCE-Luc RNA in our transduced cells is reduced transcription attributable to promoter methylation. A further consideration is that our Northern blot and RT-real time PCR results indicate that the lower steady state PCE-Luc RNA was attributable to post-transcriptional modulation.

It is now clear that steps in transcriptional and post-transcriptional control of gene expression are functionally and physically linked [25]. For example, cotranscriptional interaction with nuclear RNA processing factors is mediated by the carboxy-terminal domain (CTD) of the largest subunit of RNA polymerase II [26-29]. The CTD choreographs deposition of multiprotein complexes on nascent pre-RNAs that implement efficient export from the nucleus and translation in the cytoplasm $[25,27,28]$. The multisubunit TREX complex, which is conserved from yeast to man, links the apparently distinct processes of transcription and mRNA export [30]. Biochemical analysis of TREX has identified interaction with both intronless and intron-containing genes and determined a relationship between its cotranscriptional recruitment and premRNA retention [31]. Furthermore, the process of transcription is linked with mRNA 3 ' end formation. RNA polymerase II elongation complexes undergo multiple transitions at the 3 ' end of genes [27,32,33]. An exchange of elongation and polyadenylation/termination factors at the 3' end of genes choreographs efficient transcription termination and polyadenylation. Alteration in the tran- 

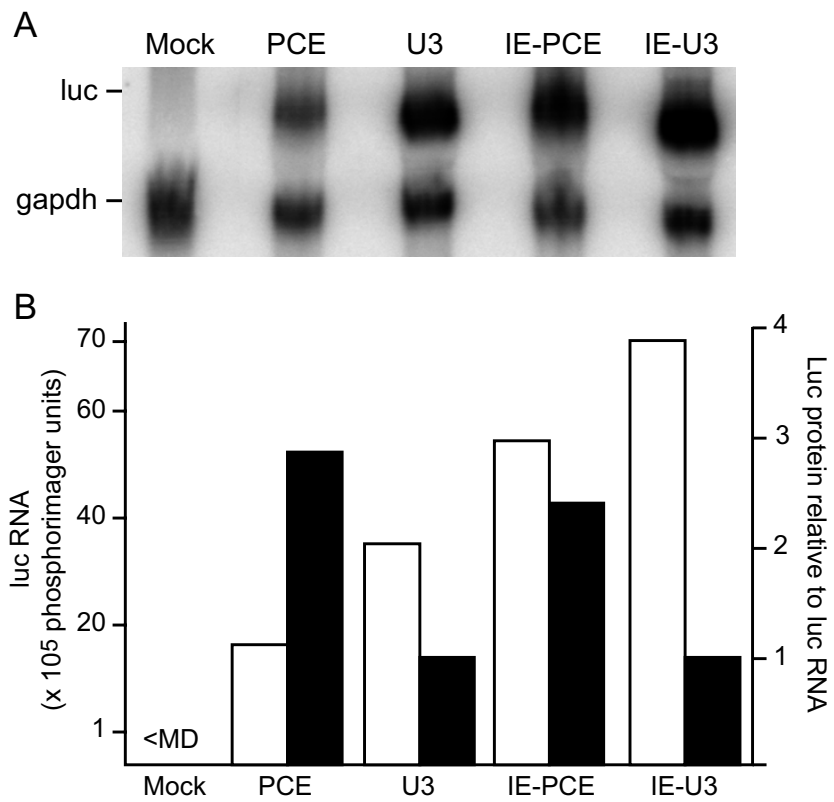

Figure 3

PCE increases translational efficiency of lentiviral vector transgene RNA in transduced cells. (A) Northern blot analysis of total cellular RNA that was isolated 48 hours post-transduction and hybridized with a probe complementary to luc or gapdh loading control (B) Graphic representation of the luc RNA in transduced cells. Black bars indicate translational efficiency relative to the corresponding U3 vector. Translational efficiency is defined as the ratio of Luc activity to luc mRNA.

scriptional activity of the promoter may invoke unexpected effects on $3^{\prime}$ end formation and reduce the steady state mRNA. Based on our results of Northern and RT-real time PCR RNA analysis we speculate that incorporation of the vector provirus into chromatin altered the cotranscriptional deposition of nuclear factors on the nascent PCELuc RNA that mediate efficient $3^{\prime}$ end formation or nuclear export. Our analysis also determined that the stimulatory effect of PCE on translation activity was sustained despite less efficient upstream steps in gene expression. This observation suggests that factors necessary for PCE translation stimulation remained available despite less cytoplasmic accumulation.

Our study using the luc transgene suggests that changes in early steps in ribonucleoprotein particle formation profoundly influenced the availability of mRNA available for translation enhancement by PCE. We project that the activity of PCE and CMV IE to co-ordinately stimulate protein output will be sustained in other transgenes. However, the unique features of any particular transgene $\mathrm{s}$ likely to influence the efficiency of 3 ' end formation or other post-transcriptional process [33,34]. Furthermore, vector integration is expected to induce epigenetic modulation of gene transcription that may profoundly affect the absolute level of RNA available for protein synthesis. The results of our study are consistent with the recent realization of tight linkage between the transcription and posttranscriptional steps in gene expression and emphasize the important role epigenetic modulation plays in vector gene expression.

\section{Conclusion}

Coordinate enhancement of transgene transcriptional and post-transcriptional expression represents a potent approach to increase transgene protein production in a broad array of gene expression systems, including lentiviral vectors, other viral vectors and non-viral gene expression plasmids. Our results show that combined introduction of the SNV PCE 5' terminal translational enhancer and CMV IE transcriptional enhancer to HIV-1 based lentiviral vectors significantly improved protein yield per molecule of intronless transgene RNA in transfected cells and in four transduced cell lines. Increasing the protein yield per RNA molecule is expected to be a useful approach in a diversity of gene expression systems. This approach could compensate for limited promoter activity observed in some in vivo studies wherein strong promoter activity was not achievable using a tissue-specific promoter [35].

\section{Methods}

\section{Plasmid construction}

The Luc vectors were derived from self inactivating pHR'CMV-GFP [36]. First, we constructed HIVSIN-Luc by insertion of a linker (5'TCGATGGATCCACTAGTC 3' and 5'TCGAGACTAGTGGATCCA 3') into the XhoI site in pHR'CMV-GFP thereby introducing an SpeI site. GFP was replaced with the luc open reading frame in the BamHIXbaI fragment from pCAM-Luc by ligation into BamHI and SpeI. pCAM-Luc was constructed by insertion of a PCR product containing luc from pGL3 (Promega, Madison, WI) with BamHI and XbaI termini into pPCR-Script CAM SK+ (Stratagene, La Jolla, CA). PCE-Luc was derived from HIVSIN-SNVLTR-GFP and U3-Luc was derived from HIVSIN-SNVU3-GFP. To construct HIVSIN-SNVLTR-GFP and HIVSIN-SNVU3-GFP, the NdeI-BamHI fragment from pHR'CMV-GFP was replaced with the NdeI-BamHI fragment that contains the SNV U3RU5 or U3 sequences of pYW100 and pYW205 [15], respectively. In order to replace the GFP fragment in HIVSIN-SNVLTR-GFP and HIVSIN-SNVU3-GFP with the luc open reading frame, DNA oligonucleotides (KB973-KB974) were annealed and ligated a the XhoI site in each vector and then NdeISpeI fragment that contains SNV U3RU5-Luc and SNV RU5-Luc from pSNVRU5luc and pSNVluc [17] was inserted to create PCE-Luc and U3-Luc, respectively. The CMV-IE enhancer region from pRL-CMV (Promega, Mad- 
Table 3: PCE correlates with reduced cytoplasmic accumulation of luc RNA in transduced cells.

\begin{tabular}{|c|c|c|c|c|c|c|}
\hline \multirow[b]{3}{*}{ Vector } & \multicolumn{4}{|c|}{ RNA copy number $\left(\times 10^{3}\right)^{a}$} & \multirow{3}{*}{$\begin{array}{l}\text { Cytoplasmic } \\
\text { accumulation }\end{array}$} & \multirow{3}{*}{$\begin{array}{c}\text { Translational } \\
\text { efficiencyc }\end{array}$} \\
\hline & \multicolumn{2}{|c|}{ Nucleoplasm } & \multicolumn{2}{|c|}{ Cytoplasm } & & \\
\hline & luc & actin & luc & actin & & \\
\hline U3-Luc & $56.7 \pm 5.4(\mathrm{I})$ & 59.3 & $25.3 \pm 2.8(1)$ & 375 & 0.45 & I \\
\hline PCE-Luc & $34.9 \pm 3.8(0.47)$ & 76.6 & $5.4 \pm 0.2(0.2)$ & 372 & 0.16 & 5 \\
\hline IE-U3-Luc & $91.3 \pm 1.5(1)$ & 69.1 & $46.8 \pm 12.9(1)$ & 417 & 0.51 & 0.5 \\
\hline IE-PCE-Luc & $96.8 \pm 2.7(0.88)$ & 82.5 & $18.3 \pm 2.7(0.4)$ & 384 & 0.19 & 3 \\
\hline
\end{tabular}

\footnotetext{
a Equivalent amounts (100 ng) of RNA from either the nucleoplasm or cytoplasm were reverse transcribed to generate cDNA and one-tenth of each reaction was quantified by real-time PCR with primers specific to luc or actin. Copy numbers were derived from standard curves generated with PGL3 luciferase plasmid in the range of $10^{1}$ to $10^{9}$ copies. Reactions were performed in duplicate and the mean and standard deviation are indicated. (), levels of luc normalized to actin relative to PCE-lacking controls, U3-Luc or IE-U3-Luc, respectively.

${ }^{b}$ Ratio of the copy number of luc RNA in the cytoplasm and nucleoplasm.

c Ratio of Luc activity to copy number of cytoplasmic luc RNA
}

ison, WI) was amplified by PCR with primers (5'TTTTTATCGATAAGCTCAATATTGGCCATATTATTCAT TGG3' and 5'TTTTCATATGCAGTTGTTACGACATTTTGGAAAG3') and ligated with NdeI-ClaI-digested PCE-Luc and U3-Luc in order to create IE-PCE-Luc and IE-U3-Luc, respectively.

\section{Transient transfection and Luciferase assay}

Transient transfections were performed on $2 \times 10^{5} 293$ cells in duplicate $60 \mathrm{~mm}$ plates. Five $\mu \mathrm{g}$ vector DNA and $0.5 \mu \mathrm{g}$ pRL-CMV (Promega, Madison, WI) were cotransfected by $\mathrm{CaPO}_{4}$ method [15]. The cells were harvested in PBS at $48 \mathrm{~h}$ post transfection, centrifuged at $1500 \times g$ for $3 \mathrm{~min}$ and resuspended in $150 \mu \mathrm{l}$ of ice-cold NP-40 lysis buffer (20 mM TrisHCl [pH 7.4], $150 \mathrm{mM} \mathrm{NaCl}, 2 \mathrm{mM}$ EDTA, and 1\% NP-40). Dual-Luciferase reporter assay (Promega, Madison, WI) was performed with $10 \mu \mathrm{l}$ lysate, $100 \mu \mathrm{l}$ Luciferase assay reagent II (Promega, Madison, WI)

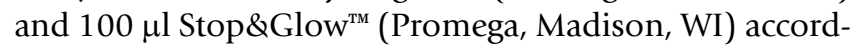
ing to manufacturer's protocol and quantified in a Lumicount luminometer (Packard Instrument Company Inc., Downers Grove, IL). The level of Ren activity was used to standardize transfection efficiency. Luc activity is presented relative to Ren activity. Luc activity in transduced cells was also determined 48 hours after transduction by the same procedure. Cells were lysed in $100 \mu \mathrm{l}$ ice-cold NP-40 lysis buffer and Luc assay was performed with $10 \mu \mathrm{l}$ lysate and $100 \mu \mathrm{l}$ Luciferase assay reagent (Promega, Madison, WI).

\section{Preparation of vector virus stocks and transduction}

Lentivirus vector stocks were produced by transient triple transfection of $293 \mathrm{~T}$ cells with $10 \mu \mathrm{g}$ of HIV-1 gag-pol packaging plasmid pCMV $\Delta$ R8.2 [37], $2 \mu \mathrm{g}$ of the pMD.G VSV glycoprotein expression plasmid [37], and $10 \mu \mathrm{g}$ of the vector plasmid by the $\mathrm{CaPO}_{4}$ method [15]. After overnight transfection of $5 \times 10^{6} 293 \mathrm{~T}$ cells in a $10-\mathrm{cm}$ plate, the cells were cultured in fresh DMEM (Invitrogen, CA), $10 \%$ FBS and $10 \mathrm{mM}$ sodium butyrate for 8 hours. The supernatants were collected at 12 hour intervals over a 60 hour time period and passed through a $0.2-\mu \mathrm{m}$ filter (Corning, NY) and concentrated by ultracentrifugation at $80,000 \times \mathrm{g}$ at $24^{\circ} \mathrm{C}$ for $2.5 \mathrm{~h}$ in a Beckman SW28 rotor. HIV-1 Gag concentration was determined by Gag p24 ELISA (Coulter, Hialeah, FL). 293, HeLa, CEMx174 and D17 cells were transduced with $4 \times 10^{5} \mathrm{pg}$ Gag in 6-well plates by spinoculation at $1500 \times \mathrm{g}$ for one hour at $32^{\circ} \mathrm{C}$ [38]. Spinoculation of 293 cells was performed in the presence of $8 \mathrm{ug} / \mathrm{ul}$ polybrene.

\section{RNA preparation}

Total RNA was isolated from approximately $5 \times 10^{5}$ cells in $0.5 \mathrm{ml}$ Trizol reagent (Invitrogen, CA) according to manufacturer's protocol. Cells were treated with $5 \mathrm{ug} / \mathrm{ml}$

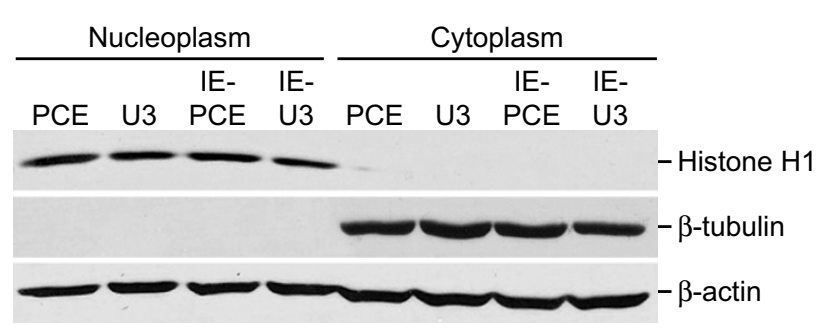

\section{Figure 4}

Western blots demonstrate appropriate subcellular fractionation of transduced cells. Equivalent amounts of each nuclear or cytoplasmic fraction were subjected to immunoblot with antiserum against the nuclear protein histone $\mathrm{HI}$; the cytoplasmic protein $\beta$-tubulin; and loading control $\beta$-actin, which is distributed in the nucleus and cytoplasm. The results determined that similar levels of protein were loaded and verified effective subcellular fractionation. 

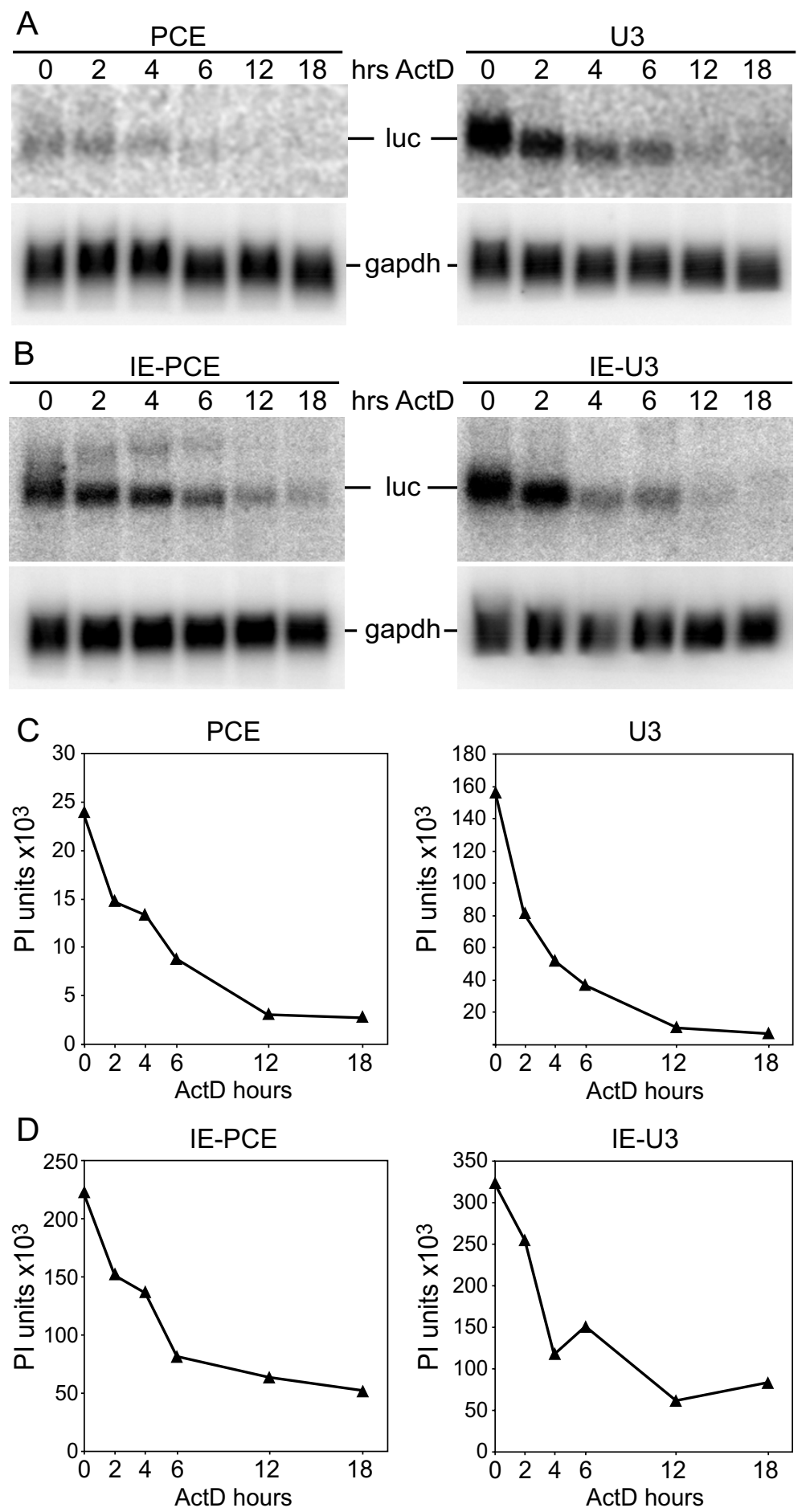

\section{Figure 5}

The half-life of luc RNA is not decreased by PCE. 293 cells transduced with PCE-Luc, U3-Luc, IE-PCE-Luc or IE-U3-Luc were treated with actinomycin $D(A c t D)$ for indicated time intervals and total RNA was isolated and subjected to Northern blot analysis with luc or gapdh complementary DNA probes. $(A, B)$ Northern blot results from a representative of two replicate experiments. The abundance of PCE-containing RNAs is lower than PCE-lacking RNAs, while the abundance of gapdh loading control was similar. (C,D) Decay curves were generated with luc RNA signal standardized to gapdh. The presence of PCE did not reduce the stability of luc RNA. 
actinomycin D for 2, 4, 6, 12 and 18 hours. To harvest nuclear and cytoplasmic RNA, a subconfluent $100 \mathrm{~mm}$ plate of cells was incubated with hypotonic lysis buffer

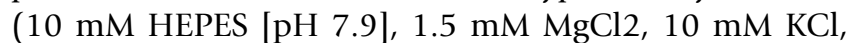
$0.5 \% \mathrm{NP} 40$, and $0.5 \mathrm{mM}$ dithiothreitol) for $10 \mathrm{~min}$ on ice andsubjected to two rounds of centrifugation at $3000 \times \mathrm{g}$ for 2 mins at $4{ }^{\circ} \mathrm{C}$. One-tenth of the nuclear pellet and cytoplasmic supernatant were reserved for Western blotting. The pellet was treated with Trizol (Invitrogen, CA) and the supernatant was treated with Trizol-LS (Molecular Research Center, Cincinnati, $\mathrm{OH}$ ) and RNA was extracted by the manufacturer's protocol.

\section{RNA analysis}

For Northern blot analysis, $5 \mu \mathrm{g}$ total RNA was separated on $1.2 \%$ agarose gels containing $5 \%$ formaldehyde, transferred to Duralon-UV membrane (Stratagene, La Jolla, CA), and incubated with either luc or gapdh DNA probes. The probes were prepared by a random-primer DNA-labeling system (Invitrogen, CA) with gel purified luc or gapdh restriction products and $[\alpha-32 \mathrm{P}] \mathrm{dCTP}$. The hybridization products were scanned with PhosphorImager (Molecular Dynamics, Sunnyvale, CA) and quantified by ImageQuant software (Molecular Dynamics, Sunnyvale, CA). Sucrose gradients were prepared from $1 \times 10^{7} 293$ cells in a T150 flask 48 hours post-transfection as described previously [17] and isolated RNA was subjected to Northern blot.

For reverse transcription, random hexamer and Sensiscript reverse transcriptase (Qiagen, Germany) were used to generate cDNA from $100 \mathrm{ng}$ of cytoplasmic or nuclear RNA. Ten percent of the cDNA preparation was used for real-time PCR with primers complementary to luciferase or actin and Quantitect SYBR Green PCR (Qiagen, Germany) in a Lightcycler (Roche, Germany). Copy numbers were derived from standard curves generated with pGL3 luciferase plasmid in the range of $10^{1}$ to $10^{9}$ copies. Reactions were performed in duplicate and the mean and standard deviation are presented.

\section{Western blotting}

Bradford assay was used to measure $50 \mu \mathrm{g}$ of protein from nuclear and cytoplasmic fractions. Proteins were separated by SDS-PAGE and transferred to nitrocellulose membrane. Immunoblotting was performed with mouse monoclonal antibodies against histone $\mathrm{H} 1, \beta$-tubulin and $\beta$-actin (Abcam, Cambridge, MA). Visualization was performed with Luminol reagent (Santa Cruz Biotechnology, Santa Cruz, CA).

\section{Competing interests}

The author(s) declare that they have no competing interests.

\section{Authors' contributions}

AY conceived of the study, carried out the vector construction, experimental evaluation, and participated in the data analysis and preparation of the manuscript. SF participated in the design of the study and carried out the statistical analysis. MDL participated in the preparation of the manuscript. KBL coordinated the design and implementation of the study, the data analysis, and the preparation of the manuscript. All authors read and approved the final manuscript.

\section{Acknowledgements}

This work was supported by National Institutes of Health National Cancer Institute Comprehensive Cancer Center grant P30 CAI6058 and Program Project grant POI CA I00730. We thank Shuiming Qian for assistance with real time PCR and Tiffiney Roberts Hartman, Kate Hayes, Cheryl Bolinger, Nicole Placek and Shuiming Qian for critical comments on the manuscript. We are grateful to Tim Vojt for illustration and formatting.

\section{References}

I. Ferrari G, Salvatori G, Rossi C, Cossu G, Mavilio F: A retroviral vector containing a muscle-specific enhancer drives gene expression only in differentiated muscle fibers. Hum Gene Ther 1995, 6:733-742.

2. Vile RG, Diaz RM, Miller N, Mitchell S, Tuszyanski A, Russell SJ: Tissue-specific gene expression from Mo-MLV retroviral vectors with hybrid LTRs containing the murine tyrosinase enhancer/promoter. Virology 1995, 21 4:307-313.

3. Grande A, Piovani B, Aiuti A, Ottolenghi S, Mavilio F, Ferrari G: Transcriptional targeting of retroviral vectors to the erythroblastic progeny of transduced hematopoietic stem cells. Blood 1999, 93:3276-3285.

4. Zhao-Emonet JC, Marodon G, Pioche-Durieu C, Cosset FL, Klatzmann D: T cell-specific expression from Mo-MLV retroviral vectors containing a CD4 mini-promoter/enhancer. J Gene Med 2000, 2:416-425.

5. Gelinas C, Temin HM: Nondefective spleen necrosis virusderived vectors define the upper size limit for packaging reticuloendotheliosis viruses. Proc Natl Acad Sci U S A 1986, 83:92II-92।5.

6. Verma IM, Somia N: Gene therapy -- promises, problems and prospects. Nature 1997, 389:239-242.

7. Braddock M, Muckenthaler M, White MR, Thorburn AM, Sommerville J, Kingsman AJ, Kingsman SM: Intron-less RNA injected into the nucleus of Xenopus oocytes accesses a regulated translation control pathway. Nucleic Acids Res 1994, 22:5255-5264.

8. Matsumoto K, Wassarman KM, Wolffe AP: Nuclear history of a pre-mRNA determines the translational activity of cytoplasmic mRNA. EMBO J 1998, 17:2107-2121.

9. Choi $T$, Huang $M$, Gorman $C$, Jaenisch $R$ : A generic intron increases gene expression in transgenic mice. Mol Cell Biol 1991, I 1:3070-3074.

10. Gudikote JP, Imam JS, Garcia RF, Wilkinson MF: RNA splicing promotes translation and RNA surveillance. Nat Struct Mol Biol 2005, I 2:80I-809.

II. Wiegand HL, Lu S, Cullen BR: Exon junction complexes mediate the enhancing effect of splicing on mRNA expression. Proc Natl Acad Sci U S A 2003, 100: I I327-I I 332.

12. Nott A, Le Hir H, Moore MJ: Splicing enhances translation in mammalian cells: an additional function of the exon junction complex. Genes Dev 2004, 18:210-222.

13. Nott A, Meislin SH, Moore MJ: A quantitative analysis of intron effects on mammalian gene expression. RNA 2003, 9:607-617.

14. Lu S, Cullen BR: Analysis of the stimulatory effect of splicing on mRNA production and utilization in mammalian cells. RNA 2003, 9:618-630.

15. Butsch M, Hull S, Wang Y, Roberts TM, Boris-Lawrie K: The 5' RNA terminus of spleen necrosis virus contains a novel posttranscriptional control element that facilitates human immuno- 
deficiency virus Rev/RRE-independent Gag production. J Virol 1999, 73:4847-4855.

16. Hull S, Boris-Lawrie K: RU5 of Mason-Pfizer monkey virus 5' long terminal repeat enhances cytoplasmic expression of human immunodeficiency virus type I gag-pol and nonviral reporter RNA. J Virol 2002, 76:10211-10218.

17. Roberts TM, Boris-Lawrie K: The 5' RNA terminus of spleen necrosis virus stimulates translation of nonviral mRNA. J Virol 2000, 74:8III-8II8.

18. Roberts TM, Boris-Lawrie K: Primary sequence and secondary structure motifs in spleen necrosis virus RU5 confer translational utilization of unspliced human immunodeficiency virus type I reporter RNA. J Virol 2003, 77: I I 973-I I 984.

19. Dangel AW, Hull S, Roberts TM, Boris-Lawrie K: Nuclear interactions are necessary for translational enhancement by spleen necrosis virus RU5. J Virol 2002, 76:3292-3300.

20. Hirano A, Wong T: Functional interaction between transcriptional elements in the long terminal repeat of reticuloendotheliosis virus: cooperative DNA binding of promoter- and enhancer-specific factors. Mol Cell Biol 1988, 8:5232-5244.

21. Ridgway AA, Kung HJ, Fujita DJ: Transient expression analysis of the reticuloendotheliosis virus long terminal repeat element. Nucleic Acids Res 1989, 17:3199-3215.

22. Sheay W, Nelson S, Martinez I, Chu TH, Bhatia S, Dornburg R: Downstream insertion of the adenovirus tripartite leader sequence enhances expression in universal eukaryotic vectors. Biotechniques 1993, 15:856-862.

23. Williams SA, Chen LF, Kwon H, Ruiz-Jarabo CM, Verdin E, Greene WC: NF-kappaB p50 promotes HIV latency through HDAC recruitment and repression of transcriptional initiation. $E M B O$ / 2006, 25: I39- I 49.

24. Hofmann A, Kessler B, Ewerling S, Kabermann A, Brem G, Wolf E, Pfeifer $A$ : Epigenetic regulation of lentiviral transgene vectors in a large animal model. Mol Ther 2006, 13:59-66.

25. Maniatis T, Reed R: An extensive network of coupling among gene expression machines. Nature 2002, 416:499-506.

26. Neugebauer KM: On the importance of being co-transcriptional. J Cell Sci 2002, I I 5:3865-387I.

27. Proudfoot NJ, Furger A, Dye MJ: Integrating mRNA processing with transcription. Cell 2002, I08:50I-5I2.

28. Reed R, Hurt E: A conserved mRNA export machinery coupled to pre-mRNA splicing. Cell 2002, 108:523-53I.

29. Jensen TH, Dower K, Libri D, Rosbash M: Early formation of mRNP: license for export or quality control? Mol Cell 2003, I I: I I 29- I I 38.

30. Strasser K, Masuda S, Mason P, Pfannstiel J, Oppizzi M, RodriguezNavarro S, Rondon AG, Aguilera A, Struhl K, Reed R, Hurt E: TREX is a conserved complex coupling transcription with messenger RNA export. Nature 2002, 417:304-308.

31. Abruzzi KC, Lacadie S, Rosbash M: Biochemical analysis of TREX complex recruitment to intronless and intron-containing yeast genes. EMBO J 2004, 23:2620-263I.

32. Ahn SH, Kim M, Buratowski S: Phosphorylation of serine $\mathbf{2}$ within the RNA polymerase II C-terminal domain couples transcription and 3' end processing. Mol Cell 2004, 13:67-76.

33. Kim M, Ahn SH, Krogan NJ, Greenblatt JF, Buratowski S: Transitions in RNA polymerase II elongation complexes at the 3' ends of genes. EMBO J 2004, 23:354-364.

34. Huertas $P$, Aguilera A: Cotranscriptionally formed DNA:RNA hybrids mediate transcription elongation impairment and transcription-associated recombination. Mol Cell 2003, |2:7||-72|.

35. Gerdes CA, Castro MG, Lowenstein PR: Strong promoters are the key to highly efficient, noninflammatory and noncytotoxic adenoviral-mediated transgene delivery into the brain in vivo. Mol Ther 2000, 2:330-338.

36. Miyoshi H, Blomer U, Takahashi M, Gage FH, Verma IM: Development of a self-inactivating lentivirus vector. J Virol 1998, 72:8150-8I57.

37. Naldini L, Blomer U, Gage FH, Trono D, Verma IM: Efficient transfer, integration, and sustained long-term expression of the transgene in adult rat brains injected with a lentiviral vector. Proc Natl Acad Sci U S A 1996, 93: I I 382-I I 388.

38. Bahnson AB, Dunigan JT, Baysal BE, Mohney T, Atchison RW, Nimgaonkar MT, Ball ED, Barranger JA: Centrifugal enhancement of retroviral mediated gene transfer. I Virol Methods 1995, 54:|3|-| 43
Publish with Biomed Central and every scientist can read your work free of charge

"BioMed Central will be the most significant development for disseminating the results of biomedical research in our lifetime. "

Sir Paul Nurse, Cancer Research UK

Your research papers will be:

- available free of charge to the entire biomedical community

- peer reviewed and published immediately upon acceptance

- cited in PubMed and archived on PubMed Central

- yours - you keep the copyright 